\title{
Stress of Conscience Questionnaire (SCQ): exploring dimensionality and psychometric properties at a tertiary hospital in Australia
}

Yangama Jokwiro ${ }^{1,5^{*}}$ (1), Elizabeth Pascoe ${ }^{1}$, Kristina Edvardsson ${ }^{1}$, Muhammad Aziz Rahman², Ewan McDonald ${ }^{1}$, Qarin Lood ${ }^{1,3}$ and David Edvardsson ${ }^{1,4}$

\begin{abstract}
Background: This study explored the psychometric properties and dimensionality of the Stress of Conscience Questionnaire (SCQ) in a sample of health professionals from a tertiary-level Australian hospital. The SCQ, a measure of stress of conscience, is a recently developed nine-item instrument for assessing frequently encountered stressful situations in health care, and the degree to which they trouble the conscience of health professionals. This is relevant because stress of conscience has been associated with negative experiences such as job strain and/or burnout. The validity of SCQ has not been explored beyond Scandinavian contexts.
\end{abstract}

Methods: A cross-sectional study of 253 health professionals was undertaken in 2015. The analysis involved estimates of reliability, variability and dimensionality. Exploratory factor analysis (EFA) and confirmatory factor analysis (CFA) were used to explore dimensionality and theoretical model fit respectively.

Results: Cronbach's alpha of 0.84 showed internal consistency reliability. All individual items of the SCQ $(N=9)$ met the cut-off criteria for item-total correlations (>0.3) indicating acceptable homogeneity. Adequate variability was confirmed for most of the items, with some items indicating floor or ceiling effects. EFA retained a single latent factor with adequate factor loadings for a unidimensional structure. When the two-factor model was compared to the one-factor model, the latter achieved better goodness of fit supporting a one-factor model for the SCQ.

Conclusion: The SCQ, as a unidimensional measure of stress of conscience, achieved adequate reliability and variability in this study. Due to unidimensionality of the tool, summation of a total score can be a meaningful way forward to summarise and communicate results from future studies, enabling international comparisons. However, further exploration of the questionnaire in other cultures and clinical settings is recommended to explore the stability of the latent one-factor structure.

Keywords: Stress of conscience, Psychometrics, Dimensionality, Exploratory factor analysis and confirmatory factor analysis, Health professionals

\footnotetext{
*Correspondence: y.jokwiro@latrobe.edu.au

${ }^{1}$ College of Science, Health and Engineering, School of Nursing

and Midwifery, La Trobe University, Melbourne, Australia
}

Full list of author information is available at the end of the article

\section{Background}

The term 'stress of conscience' has emerged to conceptualise an existential dimension of stress health professionals may develop from frequently encountered stressful situations in health care, perceived as leading to a troubled conscience [1-4]. Despite the heterogeneity of clinical settings, the generic sources of frequently encountered stressful situations across health care 
settings include perceived demanding workload, lack of support from leadership/management and staff conflict $[3,4]$. In such situations, health professionals perceived a gap between the reality of practice and their ideal practice, between structural demands and their own aspirations to provide the quality care they feel the person in need of care deserves [3-6]. Glasberg et al. [3] found that health professionals, reflecting on these stressful situations, often described punitive feelings of guilt, embarrassment and/or shame accompanying an experience of a troubled conscience. The extent to which they experienced a troubled conscience depended on individual appraisal of the stressful situation, which in turn is thought to be influenced by personal and professional ethical beliefs [1,3-5]. Hence, Glasberg et al. [3] coined the term 'stress of conscience', to highlight and explore this existential dimension of workplace stress for health professionals.

The Stress of Conscience Questionnaire (SCQ) was developed to explore stress of conscience among health professionals [3]. The impetus for Glasberg and colleagues [3] to develop the SCQ came from their review of literature, which identified a gap in tools for assessing the phenomenon associated with everyday stressful workplace situations in which health professionals perceived that their actions or inactions contradicted their conscience. In addition, ethical studies in health care linked failure to heed the voice of conscience with negative workplace outcomes such as health professionals distancing themselves from persons in need of care clients, experiencing burnout, ill-health and staff attrition [7-11]. Based on these findings, Glasberg et al. [3] developed the SCQ and hypothesised that stress of conscience could be used as an early predictor of such negative workplace outcomes. This hypothesis received empirical support in recent Scandinavian studies which explored stress of conscience in a clinical setting using the SCQ [12-15]. Therein, high levels of stress of conscience positively correlated with ratings of burnout and job strain, while negatively correlating with job satisfaction $[12,13$, 15]. Consequently, the SCQ could be a useful tool for detecting and understanding when health professionals feel stressed and are potentially on a detrimental path towards burnout and attrition. As such, the SCQ is worthy of further scrutiny beyond the Scandinavian context where the questionnaire has been validated.

The Stress of Conscience Questionnaire (SCQ), is a nine-item instrument for assessing stressful situations and the degree to which they cause a troubled conscience for health professionals [3]. This questionnaire asks respondents to first rate the frequency of which he/she perceives nine commonly occurring stressful situations present in their clinical setting on a scale of 0 'Never' to
5 'Every day' [3, 4]. Secondly, questionnaire asks respondents to rate the individual extent to which these situations are perceived as leading to a troubled conscience, on a scale from 'not at all' to 'a very troubled conscience' [3, 4]. The initial validation of the SCQ, identified two latent factors: 'internal demands' (Factor I) of the workplace, and 'external demands and restrictions' (Factor II) from sociocultural and religious beliefs [3]. Although two factors were identified, most studies have elected to present and interpret the result of the SCQ as a total sum score of all items ranging from 0 to 225 without the subscales [6, $12,13]$. Confidence in the utility of the subscales is yet to be established.

In terms of reliability, the SCQ was found to be reliable (Cronbach's $\alpha=0.83$ ) in a Swedish sample of hospital staff, as well as in samples of staff from municipal and community health care centres $[2,3,16]$. In terms of dimensionality, although the initial SCQ validation indicated two latent factors (Factor $\mathrm{I}=1$ nternal Demands and Factor II =External Demands and Restrictions), there were high cross-loadings for Items 1,3 and 8 on both factors [3]. The final factor structure included Item 1 'How often do you lack time to provide care that the patients' needs?' in both published latent factor structures [3]. The re-validation by Ahlin et al. [4] also retained two latent factors, albeit these were different to the original theoretical interpretation, and a new interpretation was not provided. Instead, Ahlin et al. [4] suggested that the SCQ could be regarded as unidimensional after exclusion of Item 6 'Is your private life ever so demanding that you don't have the energy to devote yourself to your work as you would like.' Furthermore, a study with a Finnish sample also retained two latent factors, which were inconsistent with the initial validation, and the factor outcomes were not theoretically interpreted [17]. It is plausible to conclude that, from the studies above, dimensionality of the questionnaire is yet to be settled, which warrants further exploration of the questionnaire in other contexts. Indeed, Glasberg et al. [3] and Ahlin et al. [4] also recommended exploration of the SCQ in other clinical settings, professions and cultural context.

To conclude, it seems pertinent to further explore the psychometric properties and dimensionality of the SCQ within an Australian context to provide further scrutiny beyond Scandinavian contexts. Findings could provide data and confidence (if upheld) to collect and compare results from the SCQ scale internationally.

\section{Aim of the study}

This study aimed to explore psychometric properties and dimensionality of the SCQ in a sample of health professionals from a tertiary level hospital in Melbourne, Australia. 


\section{Methods}

\section{Study sample}

The study was conducted in a sample of 253 nurses, medical doctors and allied health professionals across emergency, medical and surgical wards and a geriatric ward in a 560-bed Australian tertiary-level hospital. Administrative staff and other auxiliary staff members were excluded. A total of 500 questionnaires were distributed and 253 questionnaires where returned (51\%).

\section{Stress of conscience questionnaire (SCQ)}

The English version of the SCQ presented by Ahlin et al. [4] was used in this study. The questionnaire achieved a Cronbach's alpha of 0.83 for the nine-item total validation in a Swedish context [4]. The SCQ is composed of nine two-part items (Part A and Part B) measuring commonly occurring stressful situations present in their clinical setting and the extent these situations are perceived as leading to a troubled conscience [22]. Part A assesses the frequency of such situations on a six-point Likert scale ranging from 0 (never) to 5 (every day). Part $\mathrm{B}$ assesses the extent to which these situations are perceived as leading to troubled conscience, on a visual analogue scale that runs from 0 (no, it does not trouble my conscience at all) to 5 (yes, it troubles my conscience greatly). The SCQ individual item score (index score) is obtained by multiplying part $A$ and $B$ ratings to generate a range from 0 to 25 points.

\section{Study procedure}

The questionnaires which included demographic data such as age, sex and experience were delivered to the wards in a box that was stored in the nurse unit manager's office, together with a sealed return box. The questionnaires were handed out to the staff during ward hand over. A participant information letter, which outlined the purpose of the study and guaranteed anonymity, accompanied each questionnaire. Participants were informed in the letter that consent was implied if they voluntarily completed and returned the questionnaire. All data were collected in October 2015 from voluntary participants.

\section{Statistical analysis}

Questionnaire variability was analysed in terms of floor and ceiling effects, and a cut off score of $>15 \%$ on the minimum and maximum scores for each item was set [18]. Internal consistency reliability was evaluated by Cronbach's alpha $(>0.7)$, item-total correlations $(>0.3)$ and inter-item correlations (0.2-0.4) [19, 20]. Exploratory factor analysis (EFA) was used to investigate instrument dimensionality. Kaiser-Meyer Olkin measure of sampling adequacy (KMO) and Bartlett's test of sphericity were analysed first to determine suitability of the data to undergo factor analysis, the cut of were $>0.6$ and $<1.0$ and statistical significance $(\mathrm{p}<0.001)$ respectively [21-23]. Confirmatory factor analysis (CFA) was used to examine the adequacy of the resulting factor model. To evaluate model fit, this study used a range of absolute and incremental model fit indices, including the ratio of chi-square to degrees of freedom (X2/df), comparative fit index (CFI), adjusted goodness of fit (AGFI); root mean square error of approximation (RMSEA), PCLOSE and Akaike Information Criteria (AIC), [24-26]. The factor structure in this study was also compared to the two-factor model proposed by Glasberg et al. [3]. The Statistical Package for Social Sciences (SPSS) and AMOS, Version 24.0 was used for statistical analysis of the data (SPSS, Chicago, IL, USA).

\section{Ethical considerations}

The study adhered to the principles of the Helsinki Declaration and the National Health and Medical Research Council's statement for the ethical conduct in human research. The study was approved by the Human Research Ethics Committee (LNR15, 299) to use implied informed consent, which meant that consent was obtained from participants if and when they returned a completed study questionnaire after reading the information letter which outlined the process. The reasoning behind this was to protect participant anonymity, privacy and autonomy, as far as possible by distributing study questionnaires at ward levels, making sure the informed consent to participate was made actively, individually and independently by those staff that completed and returned study questionnaires. This means that informed consent was implied in their active, autonomous and anonymous decision to participate.

\section{Results}

\section{Sample characteristics}

The sample consisted predominantly of registered nurses $(n=205,81 \%)$, who were female $(n=217,85.8 \%)$ as indicated in Table 1. The mean age was $32.9(\mathrm{SD}=10.0)$ and the average length of time working in the ward was 9.2 years $(\mathrm{SD}=9.0)$. The employment status was divided almost equally between full time (51.1\%) and part-time/ casual workers $(48.9 \%)$. The specialty areas from which the sample was drawn are indicated in Table 1.

\section{Variability}

Table 2 summarises item performance of the SCQ. The table presents Part A and Part B of the questions separately and as index scores (Part A multiplied by Part B). Ceiling effects were detected for Items 1A and 3A (39.4\% and $17.4 \%$ ) and a floor effect was detected in Items $2 \mathrm{~A}$ (40.9\%), $4 \mathrm{~A}$ and $4 \mathrm{~B}$ (61.6\% and $20.3 \%), 5 \mathrm{~A}$ and $5 \mathrm{~B}(51.8 \%$ 
Table 1 Sample Characteristics

\begin{tabular}{ll}
\hline & $\boldsymbol{N}(\%)$ \\
\hline Gender $(n=253)$ & $217(85.8)$ \\
Women & $36(14.2)$ \\
Men & \\
Qualification $(n=253)$ & $205(81)$ \\
Registered Nurses & $18(7.1)$ \\
Enrolled nurses & $10(4.0)$ \\
Medical Doctors & $6(2.4)$ \\
Physiotherapists & $2(0.8)$ \\
Occupational therapists & $12(4.7)$ \\
Others & \\
Age Group $(n=253)$ & $126(49.8)$ \\
20-29 years & $72(28.5)$ \\
30-39 years & $24(9.4)$ \\
40-49 years & $31(12.3)$ \\
50+ & \\
Specialty area $(n=253)$ & $59(23.3)$ \\
Emergency ward & $80(31.6)$ \\
Surgical wards & $83(32.8)$ \\
Medical wards & $31(12.3)$ \\
Geriatric ward &
\end{tabular}

and $15.9 \%)$, and $6 \mathrm{~A}$ and $6 \mathrm{~B}(36.2 \%$ and $16.7 \%), 7 \mathrm{~A}$ (15.9\%), 8A (22.5\%) and $9 \mathrm{~A}$ and $9 \mathrm{~B}$ (47.8\% and $19.6 \%)$ as shown on Table 2.

\section{Reliability}

All individual items met the cut-off criteria for item-total correlations above 0.3 as shown in Table 2. Further evidence of satisfactory internal consistency reliability was indicated by a total Cronbach's alpha of 0.84 , not being increased by deleting any of the items. The results were also consistent if the Part A and Part B questions were measured for reliability separately or as combined index scores (Part A multiplied by Part B).

\section{Dimensionality}

Exploratory factor analysis (EFA) was conducted on the index scores (Part A multiplied by Part B) as proposed by Glasberg et al. [3]. All SCQ items had correlations within the recommended range of 0.30 to 0.70 with at least one other item. The Kaiser-Meyer-Olkin (KMO) was 0.84 and Bartlett's test of sphericity was significant $(\mathrm{p}<0.001)$. The Kaiser criteria of an eigenvalue $>1$, the Cattel scree test and parallel analysis yielded one single latent factor which explained $44 \%$ of the total variance. All items met the criterion of communalities exceeding 0.3 in the principle component analysis (PCA). The unrotated factor matrix loadings were greater than 0.55 (Table 2). When maximum likelihood extraction and principle axis factoring was performed, a single factor structure was also retained with adequate factor loadings.

The single latent factor was compared with the two latent factors proposed by Glasberg et al. (2006) (i.e. Factor $\mathrm{I}=$ Internal Demands and Factor $\mathrm{II}=$ External Demands and Restrictions) as a one-factor and a twofactor model. The one-factor model was associated with good model fit $(\mathrm{CMIN} / \mathrm{DF}=1.340 ; \quad \mathrm{P}$-value $=0.146$; $\mathrm{CFI}=0.990 ; \quad \mathrm{AGFI}=0.948 ; \quad \mathrm{RMSEA}=0.037 \quad$ and PCLOSE $=0.704)$ as shown in Table 3. Factor loadings ranged from 0.40 to 0.77 as shown in Fig. 1. In contrast, the two-factor model fit indicated that some fit indices were not adequate $(\mathrm{CMIN} / \mathrm{DF}=3.521 ; \mathrm{P}$-value $=0.000$; $\mathrm{CFI}=0.910 ; \quad \mathrm{AGFI}=0.871 ; \quad \mathrm{RMSEA}=0.100 \quad$ and PCLOSE $=0.000$ ). Factor loadings for the two-factor model ranged from 0.42 to 0.75 and two latent factors also closely correlated, which suggests a lack of distinct factors as displayed in Fig. 2. When the two-factor model was compared to the one-factor model, the latter received the lowest AIC score $(\mathrm{AIC}=123.768)$ and the chi-square test was not significant $(\mathrm{P}$-value $=0.146)$, which also supported the one-factor model as better fitting the data.

\section{Discussion}

Exploration of the psychometric properties and dimensionality of the Stress of Conscience Questionnaire (SCQ), based on a sample of health professionals working in a tertiary-level Australian hospital, indicated satisfactory reliability and variability estimates. Also, the scale was found to be unidimensional as one single latent factor was confirmed. This suggests SCQ results can be aggregated, interpreted, and communicated as one summative score aggregating all individual 9-Items without the use of any subscales.

Although most SCQ items showed adequate variability, Item $1 \mathrm{~A}$ and item $3 \mathrm{~A}$ had a ceiling effect and a few other items showed a floor effect, indicating that more than $15 \%$ of results were aggregating at the top or bottom scoring alternative. The limited variability among these items could be problematic if the SCQ is used to assess variance over time or in pre and post interventions studies [24], and it remains unknown if this is due to data characteristics of this study or shortcomings in the questionnaire. Further studies would be valuable to explore the variability of these items. Higher mean scores obtained for Items 1 'do you often lack time to provide the care? Item 3 'Do you ever have to deal with incompatible demands?' and Item 7 'Does your work affect your private life?' were consistent with previous studies [12, 13]. Although Ahlin et al. [4] suggested removing Item 6 'Is your private life ever so demanding that you don't have the energy to devote yourself to your work as you would like?, this study demonstrated that the item should be retained 


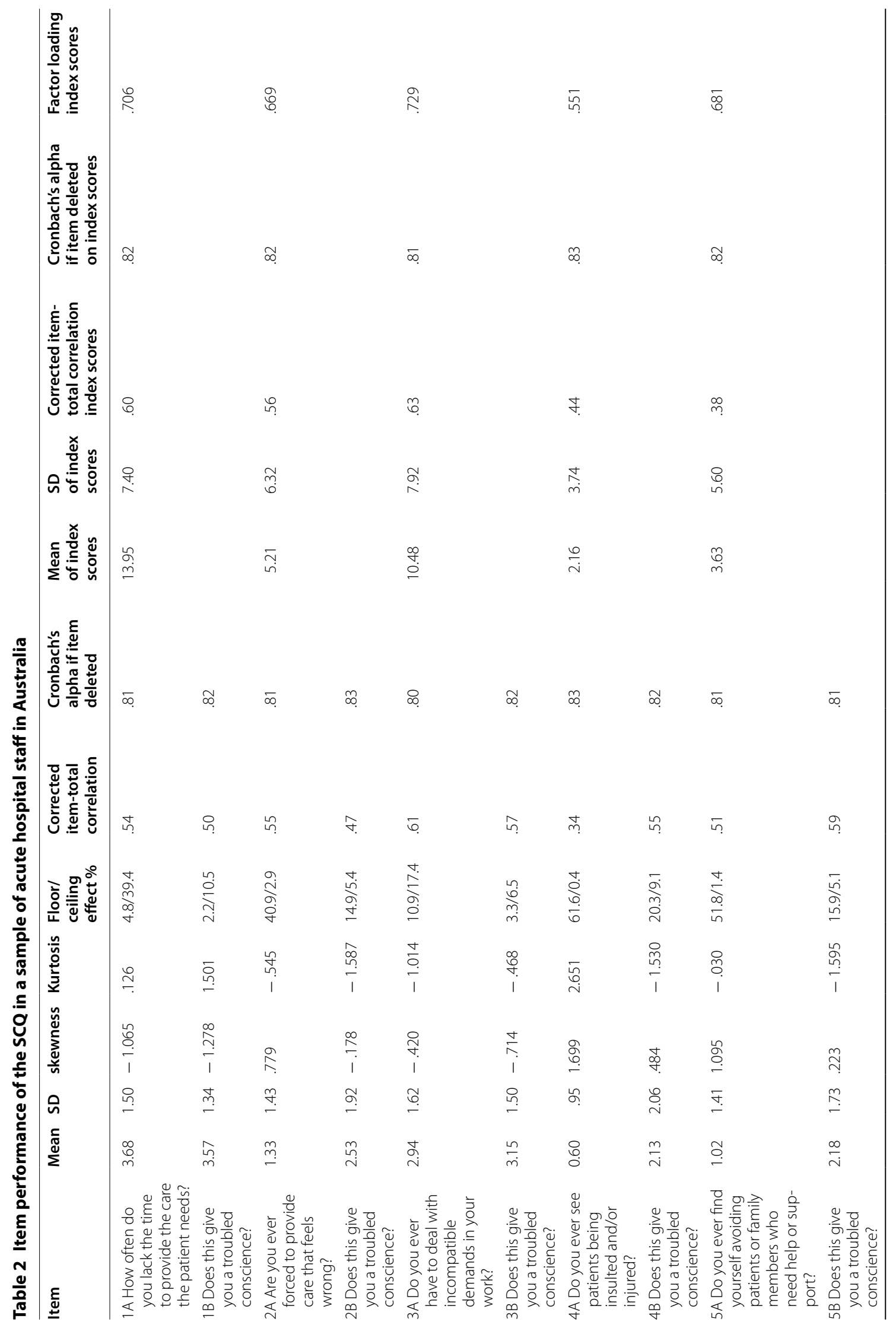




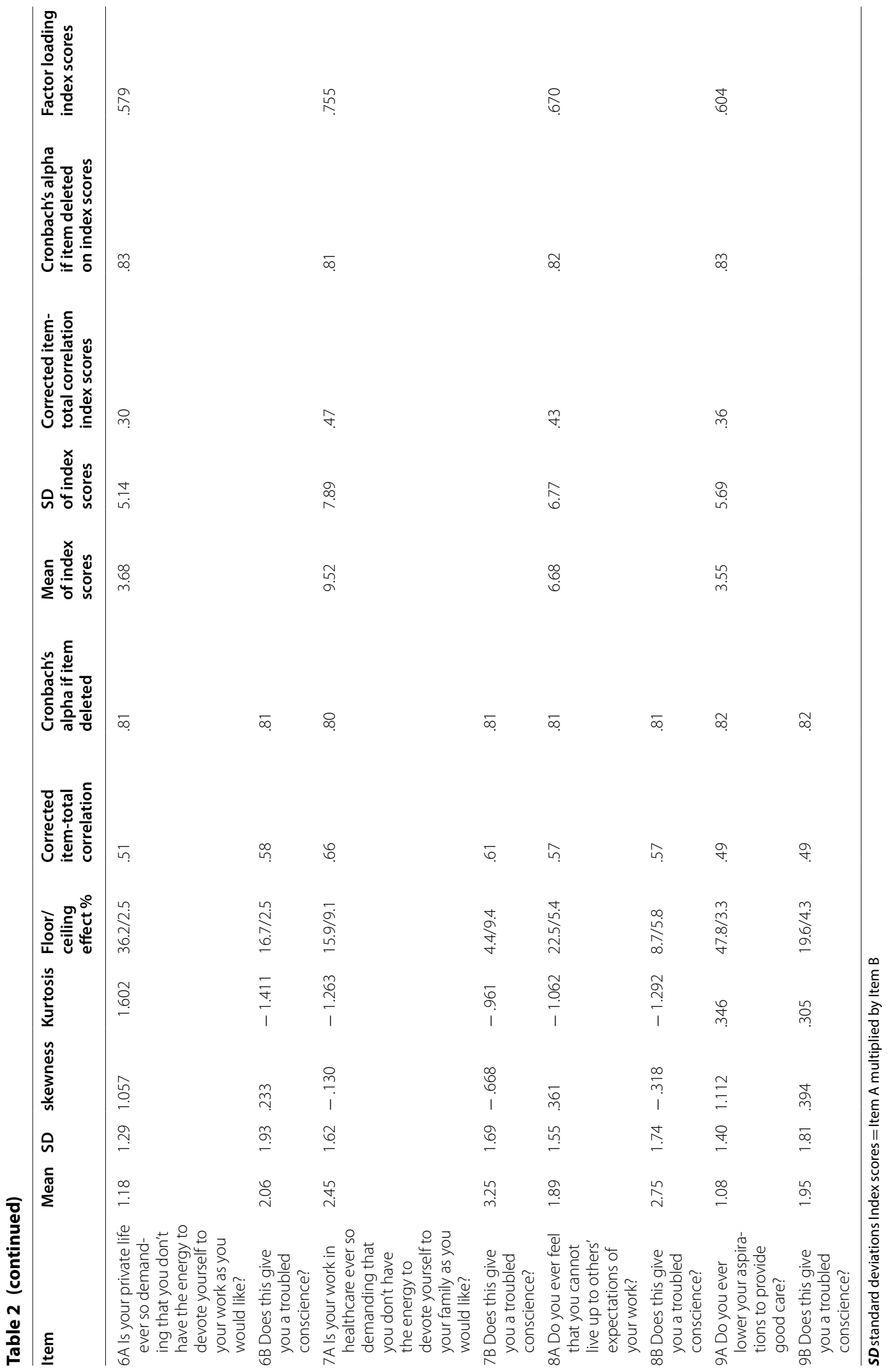


Table 3 Model fit summary

\begin{tabular}{|c|c|c|c|c|c|c|c|}
\hline Model & CMIN/DF & AGFI & CFI & RMSEA & PCLOSE & $\begin{array}{l}\text { CMIN } \\
\text { Chi-square value }\end{array}$ & AIC \\
\hline $\begin{array}{l}\text { Reference values } \\
\text { Jackson et al. } 2009 \\
\text { Hair et al. } 2010\end{array}$ & $\begin{array}{l}<3 \text { Good } \\
<5 \text { permissible }\end{array}$ & $>0.80$ & $\begin{array}{l}>0.95 \\
\text { great } \\
>0.90 \text { tra- } \\
\text { ditional } \\
>0.80 \\
\text { permis- } \\
\text { sible }\end{array}$ & $\begin{array}{l}<0.05 \text { good } \\
0.5-0.10 \text { moderate } \\
>0.1 \text { bad }\end{array}$ & $>0.05$ & P-value $>0.05$ & $\begin{array}{l}\text { The model with a lower } \\
\text { value demonstrates better } \\
\text { model fit }\end{array}$ \\
\hline 1-Factor Model & 1.340 & .948 & .990 & .037 & .704 & $\begin{array}{l}53.768 \\
\text { P-value }=.146\end{array}$ & 123.768 \\
\hline 2-Factors Model & 3.521 & .871 & .910 & .100 & .000 & $\begin{array}{l}80.982 \\
\text { P-value }=.000\end{array}$ & 142.81 \\
\hline
\end{tabular}

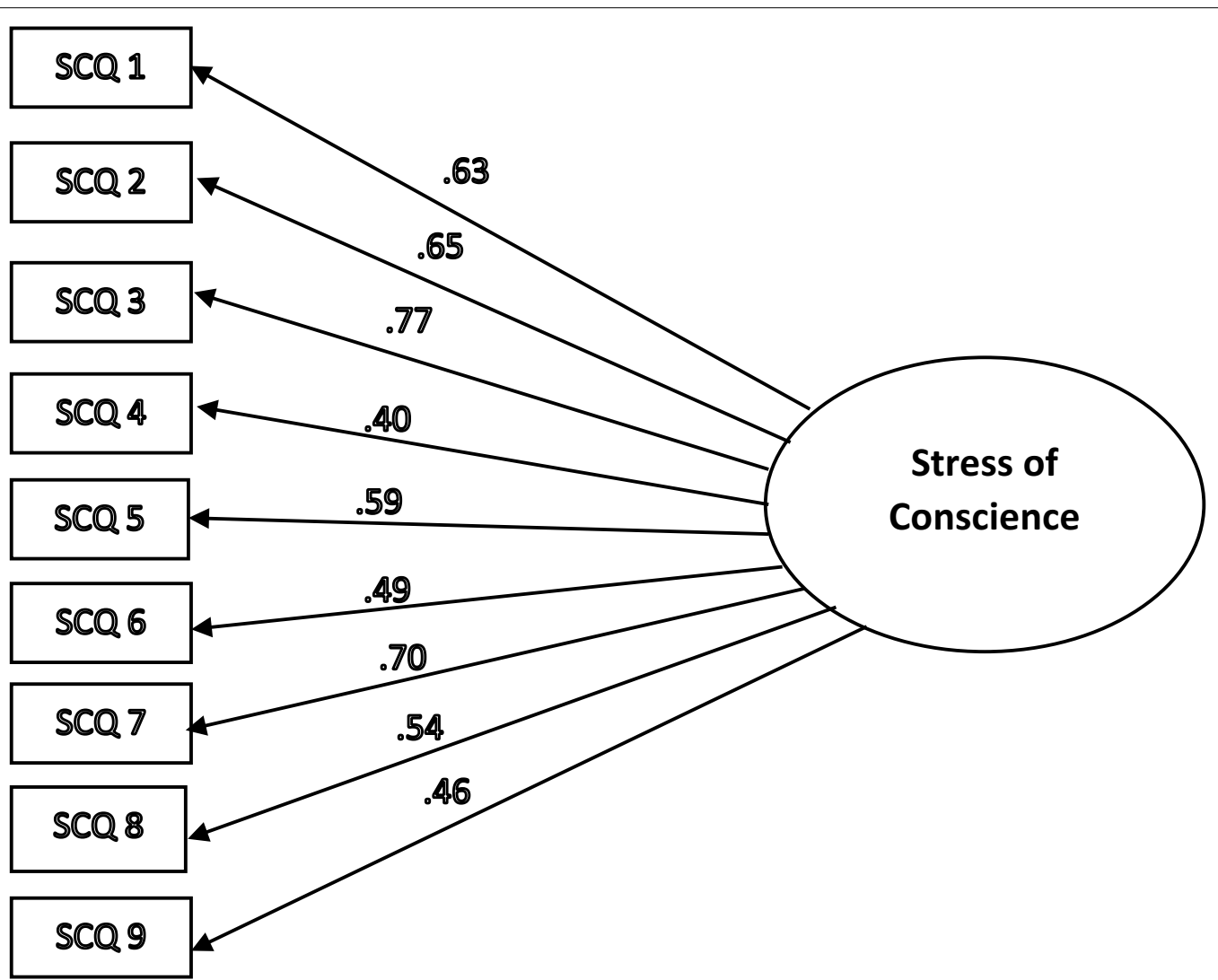

Fig. 1 Confirmatory Factor Analysis (CFA) of the one-factor structure proposed in this study using AMOS software. SCQ =Stress of Conscience Questionnaire. SCQ 1 to $9=$ Stress of Conscience Questionnaire Index Score Items (Part A multiply by Part B of each item). CFA identifying variance was 1 and factor loading cut-off was set $>0.4$

due to having an adequate correlation with other items and a factor loading of 0.58 . The Cronbach's alpha of 0.84 and item-total correlations (ranging between 0.30 and 0.70 ) indicated that all items reliably measured a single underlying construct with acceptable homogeneity [24]. Reliability scores were stable both when Part A and Part $B$ questions were treated separately or as index scores
(Part A multiplied by Part B) as indicated in Table 2. Initial validation by Glasberg et al. [3] and subsequent revalidation by Ahlin et al. [4] also showed adequate internal consistency, indicating stability of the SCQ across different samples and settings.

This is the first study to explore and confirm unidimensionality of the SCQ in an English-speaking 


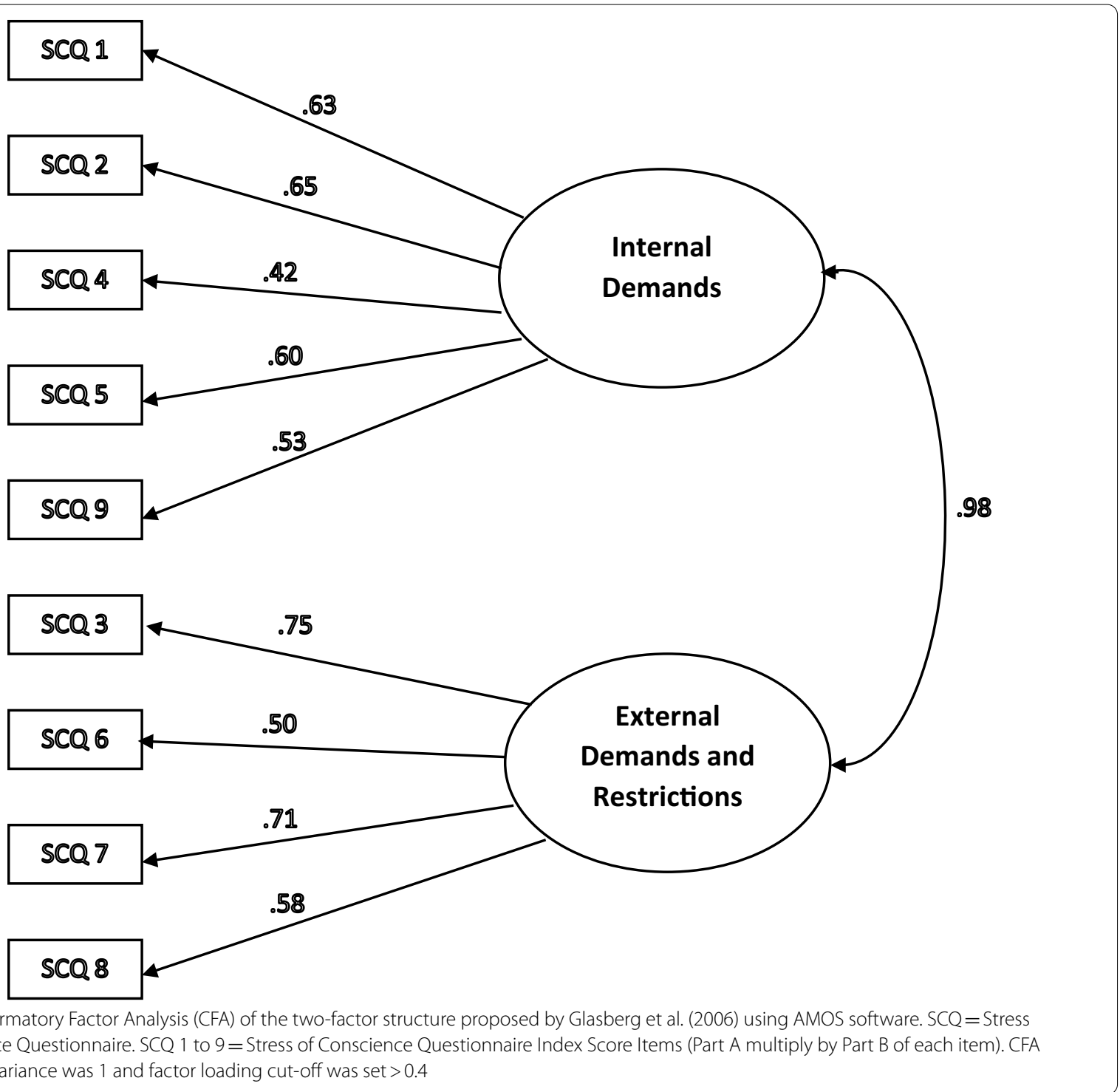

context, which adds further evidence and confidence for use of the Stress of Conscience Questionnaire. The results of the EFA yielded a single latent factor, which explained $44 \%$ of the total variance. Factor loading of each item was greater than 0.55 on the first extraction factor, meaning that all items were indicators of the latent factor, Stress of Conscience. However, the studies by Glasberg et al. [3], Ahlin et al. [4] and Saarnio et al. [17] retained two latent factors. Although these studies produced two stable latent factors, there were higher cross loading on both latent factors. The initial validation by Glasberg et al. [3] included item 1 in both latent factor solutions. In addition, the rotated two-factor solution by Ahlin et al. [4] was inconsistent with the theoretical interpretations proposed by Glasberg et al.
[3]. According to Ahlin et al. [4], all items except for Item 6 had higher loadings on the first factor (all >0.48) compared with the second factor in the unrotated solution, which indicated a unidimensional structure. Ahlin et al. [4] concluded that this outcome could be a result of the index scores, which equalizes stressors and troubled conscience (Part A multiply by Part B). The factor structure in this study meets the criteria for unidimensionality, confirming that calculations of the arithmetic mean, from the summation of all index scores, provides meaningful data for interpretation, comparison and communication of results. This was reinforced by the CFA which indicated that the one-factor structure had better model fit $(\mathrm{CMIN} / \mathrm{DF}=1.340 ; \mathrm{P}$-value $=0.146$; $\mathrm{CFI}=0.990 ; \quad \mathrm{AGFI}=0.948 ; \quad \mathrm{RMSEA}=0.037 \quad$ and 
PCLOSE $=0.704)$ as compared to the two-factor model $(\mathrm{CMIN} / \mathrm{DF}=3.521 ; \quad$ P-value $=0.000 ; \quad \mathrm{CFI}=0.910$; $\mathrm{AGFI}=0.871 ; \mathrm{RMSEA}=0.100$ and $\mathrm{PCLOSE}=0.000$ ) Although some model fit indices were also acceptable for the two-factor model, the latent factors were highly correlated, suggesting that they were not distinct factors. The one-factor model also received the lowest AIC score $(\mathrm{AIC}=123.768)$ and the chi-square test was not significant $(P$-value $=0.146)$, indicating that this was the most parsimonious model for the data analysed [25, 26]. Therefore, the results of this study indicate that the SCQ is best conceptualized as a unidimensional measure with a single latent factor.

There were some limitations of this study of importance to consider. The self-reported data may be liable to social desirability bias, and thus needs cautious interpretation. However, the data collection process was anonymous to encourage participants to be truthful. The cross-sectional and contextual location of the data implies cautious interpretation of the findings, and further data from other contexts and countries is needed. Results from reliability and dimensionality testing also need to be interpreted with caution, as the criteria for assessing goodness of fit are relative rather than absolute [25]. The sample consisted mainly of female nurses, which may limit generalizability for different genders and other professions. The stability of the single latent factor also needs to be assessed as the parallel analysis factor explained $44 \%$ of the total variance.

\section{Conclusion}

The Stress of Conscience Questionnaire achieved satisfactory reliability and variability for assessing frequently encountered stressful situations, and the degree individual health professionals experience a troubled conscience in their workplace. The factor structure in this study met the criteria for unidimensionality, suggesting that a simple sum score of items is a feasible and reliable way forward to quantify and explore this phenomenon across countries, and different contexts. Highlighting and discussing ethical challenges is at core of healthcare, and the SCQ can be a significantly helpful tool for clinical managers in this process.

\section{Abbreviations}

AGFI: Adjusted goodness of fit; CFI: Comparative Fit Index; CFA: Confirmatory factor analysis; EFA: Exploratory factor analysis; KMO: Kaiser-Meyer Olkin measure of sampling adequacy; RMSEA: Root mean square error of approximation; SCQ: Stress of Conscience Questionnaire.

\section{Acknowledgements}

The authors would like to thank the nurses who participated in the study.

\section{Authors' contributions}

Study Design: YJ, DE; data collection and analysis; YJ, DE, MR, KE, LP, EM, QL and manuscript preparation YJ, DE, MR, KE, LP, EM, QL. All authors read and approved the manuscript before submission.

\section{Funding}

This study did not receive any financial support from grants, public funds or not-for-profit organisations.

\section{Availability of data and materials}

The dataset analysed during this study is available from the corresponding author on reasonable request.

\section{Ethics approval and consent to participate}

All participants received an information letter which outlined the purpose of the study, invited them to participate and guaranteed anonymity. The letter was accompanied by the study questionnaire and consent was implied if the participant returned the questionnaire. The Austin Health (Melbourne, Australia) Human Research Ethics Committee approved the study and the ethics reference number is LNR15, 299.

\section{Consent for publication}

Not applicable.

\section{Competing interests}

The authors declare no potential competing interest with respect to the research, authorship, and publication of this article.

\section{Author details}

${ }^{1}$ College of Science, Health and Engineering, School of Nursing and Midwifery, La Trobe University, Melbourne, Australia. ${ }^{2}$ School of Nursing and Healthcare Professions, Federation University, Berwick Campus, Melbourne, Australia. ${ }^{3}$ Institute of Neuroscience and Physiology, Department of Health and Rehabilitation, Sahlgrenska Academy, Centre for Ageing and Health - AgeCap, University of Gothenburg, Box 455, 40530 Gothenburg, Sweden. ${ }^{4}$ Department of Nursing, The Medical Faculty, Umea University, Umeå, Sweden. ${ }^{5}$ School of Nursing and Midwifery, College of Science, Health and Engineering, La Trobe University, Bundoora, Australia.

Received: 6 February 2020 Accepted: 12 October 2020 Published online: 20 October 2020

\section{References}

1. Jensen A, Lidell E. The influence of conscience in nursing. Nursing Ethics. 2009;16(1):31-42. https://doi.org/10.1177/0969733008097988.

2. Alkrisat M, Alatrash M. Stress of conscience: concept clarification. Online J Health Ethics. 2016;12:1. https://doi.org/10.18785/ojhe.1201.02.

3. Glasberg AL, Eriksson S, Dahlqvist V, Lindahl E, Strandberg G, Soderberg A, Norberg A. Development and initial validation of the stress of conscience questionnaire. Nurs Ethics. 2006;13(6):633-48. https://doi. org/10.1177/0969733006069698.

4. Ahlin J, Ericson-Lidman E, Norberg A, Strandberg G. Revalidation of the perceptions of conscience questionnaire (PCQ) and the stress of conscience questionnaire (SCQ). Nurs Ethics. 2012;19(2):220-32. https://doi. org/10.1177/0969733011419241.

5. Dahlqvist V, Eriksson S, Glasberg A, Lindahl E, Lutzen K, Strandberg G, Soderberg A, Sorlie V, Norberg A. Development of the perceptions of conscience questionnaire. Nurs Ethics. 2007;14:181-93.

6. Juthberg C, Eriksson S, Norberg A, Sundin K. Perceptions of conscience in relation to stress of conscience. Nurs Ethics. 2007;14(3):329-43. https:// doi.org/10.1177/0969733007075868.

7. Pask EJ. Guilt and nursing practice: implications for nurse education and the climate of care. Nurs Ethics. 1994;1:80-5.

8. Holly CM. The ethical quandaries of acute care nursing practice. J Prof Nurs. 1993;9:110-5.

9. Cleary $M$, Horsfall J. Integrity and mental health nursing: Factors to consider. Issues Mental Health Nurs. 2013;34(9):673-7. 
10. Price DM, Murphy PA. Staff burnout in the perspective of grief theory. Death Educ. 1984;8:47-58.

11. Norberg A, Norberg B, Bexell G. Ethical problems in feeding patients with advanced dementia. Br Med J. 1980;281:847-8.

12. Juthberg C, Eriksson S, Norberg A, Sundin K. Stress of conscience and perceptions of conscience in relation to burnout among care-providers in older people. J Clin Nurs. 2008;17(14):1897-906. https://doi.org/10.111 1/j.1365-2702.2007.02184.x.

13. Juthberg C, Eriksson S, Norberg A, Sundin K. Perceptions of conscience, stress of conscience and burnout among nursing staff in residential elder care. J Adv Nurs. 2010;66(8):1708-18. https://doi.org/10.111 1/j.1365-2648.2010.05288.x.

14. Ericson-Lidman E, Strandberg G. Troubled conscience related to deficiencies in providing individualised meal schedule in residential care for older people-a participatory action research study. Scand J Caring Sci. 2015;29(4):688. https://doi.org/10.1111/scs.12197.

15. Orrung Wallin A, Jakobsson U, Edberg AK. Job strain and stress of conscience among nurse assistants working in residential care. J Nurs Manag. 2015;23(3):368-79. https://doi.org/10.1111/jonm.12145.

16. Orrung WA. Psychometric properties concerning four instruments measuring job satisfaction, strain, and stress of conscience in a residential care context. Arch Gerontol Geriatr. 2013;57(2):162.

17. Saarnio R, Sarvimaki A, Laukkala H, Isola A. Stress of conscience among staff caring for older persons in Finland. Nurs Ethics. 2012;19(1):104-15. https://doi.org/10.1177/0969733011410094.

18. Terwee CB, Bot SDM, de Boer MR, van Der Windt DIAWM, Knol DL, Dekker J. Quality criteria were proposed for measurement properties of health status questionnaires. J Clin Epidemiol. 2007;60(1):34-42. https://doi. org/10.1016/j.jclinepi.2006.03.012.

19. Field AP. Discovering statistics using IBM SPSS statistics, 5th. edition. London: California SAGE Publications; 2018.

20. Streiner DL. Health measurement scales: a practical guide to their development and use. 4th ed. Oxford: Oxford University Press; 2008.

21. Bartlett MS. Properties of Sufficiency and Statistical Tests. Proc R Soc Lond Ser A Math Phys Sci (1934-1990). 1937;160(901):268-82. https://doi. org/10.1098/rspa.1937.0109.

22. Cerny BA, Kaiser HF. A study of a measure of sampling adequacy for factor-analytic correlation matrices. Multivar Behav Res. 1977;12(1):43-7. https://doi.org/10.1207/s15327906mbr1201_3.

23. Kaiser H. An index of factorial simplicity. Psychometrika. 1974;39(1):31-6. https://doi.org/10.1007/BF02291575.

24. Hair JF. Multivariate data analysis (Pearson new international seventh edition. Joseph F. Hair, Jr., William C. Black, Barry J. Babin, Rolph E. Anderson (ed) Harlow, Essex Pearson. 2014.

25. Jackson DL, Gillaspy JA, Purc-Stephenson R. Reporting practices in confirmatory factor analysis: an overview and some recommendations. Psychol Methods. 2009;14(1):6-23. https://doi.org/10.1037/a0014694.

26. Burnham K, Anderson D. Model selection and multimodal inference. New York: Springer; 2002.

\section{Publisher's Note}

Springer Nature remains neutral with regard to jurisdictional claims in published maps and institutional affiliations.
Ready to submit your research? Choose BMC and benefit from:

- fast, convenient online submission

- thorough peer review by experienced researchers in your field

- rapid publication on acceptance

- support for research data, including large and complex data types

- gold Open Access which fosters wider collaboration and increased citations

- maximum visibility for your research: over $100 \mathrm{M}$ website views per year

At BMC, research is always in progress.

Learn more biomedcentral.com/submissions 